\title{
DETERMINANTS OF THE COMPENSATION AND MOBILITY OF SGHOOL SUPERINTENDENTS
}

\author{
RONALD G. EHRENBERG, RICHARD P. CHAYKOWSKI, and \\ RANDY A. EJHRENBERG*
}

\begin{abstract}
Analyzing 1978-89 panel data from more than 700 New York State school districts, the authors find evidence that school superintendents were rewarded, both by higher salary increases and by enhanced opportunities to move to better-paying jobs, for having low school tax rates and high educational achievement within their districts, relative to the values of those variables in comparable school districts in the state. The rewards were, however, quite small. The analysis ilso suggests that the superintendents themselves did not significantly influence either school tax rates or educational test scores in their districts.
\end{abstract}

$T^{*}$

HE April 1983 report of the National Commission on Excellence in Education, A Nation at Risk, focused pubiic attention on the need to reform public education. A proposal to institute merit pay plans for teachers, which bistorically

\footnotetext{
* Ronald Ehrenberg is Irving M. Ives Professor of Industrial and Labor Relations and Economics at Cornell University and Research Associate at the National Bureau of Economic Research; Richard Chaykowski is Assistant Professor, Departments of Economics and Industrial Relations, Queen's Univer. sity, Kingsion, Ontario; and Randy Ehrenberg is Vice Principal at Dewitt Middle School, Ithaca City School Disirict, Ithaca, New York. The authors thank the numerous school superintendents who responded to the survey used in the paper; the staff of the Cornell Institute of Social and Economic Research who acquired a number of the necessary data tapes; Eileen Driscoll, who facilitatcd the use of these data; and, especially, Jeffrey Keefe, who provided valuable assistance coding and analyzing data during the early stages of the project. They also thank numerous colleagues at Cornell, the NBER and other institutions, and two referees for comments on carlier drafts. The first draft of this paper was written while Ronald Ehrenberg was a Visiting Professor at Tel-Aviv University, and he is graleful to that university for its hospitality.
}

have not met with much success in public education, was among the most hotly debated recommendations in the report. In contrast, little attention has been directed to the role that educational administrators (school principals and superintendents) play in the educational process or to the ways in which they are compensated. Given the large role administrators play in recruiting and supervising teachers, designing curricula, setting educational goals, and managing school district resources, they might reasonably be supposed influential in determining what and how much students learn as well as how much taxpayers pay for public educa. tion.' Their relative neglect by participants in the educational debate in recent years is therefore surprising.

Although there have been a few case studies and statistical analyses of superintendents' turnover and mobility, very little

\footnotetext{
'See Ehrenberg, Chaykowski, and Ehrenberg (1986) for citations to the "effective school" literature that siresses this point.
} 
is known about the factors that influence the compensation of school administrators or their mobility. In particular, it is not known whether superior "performance" by a school district results in rewards for its administrators in the form of higher compensation or greater opportunities for mobility to higher-paying positions. That question is clearly important for policy debate; if it is found that school administrators' compensation is not even implicitly tied to their districts' "performance," a case can be made for building explicit incentives for performance into their compensation arrangements.

To shed light on this issue, we have analyzed the compensation and mobility of school superintendents in New York State during the 1978-79 to 1982-83 period. Our focus is on school superintendents rather than principals not only because the former are the chief operating officers of school districts, but because their salaries are determined through individual "negotiations" with school boards and their salary data were made available to us, whereas school principals-especially those in large districts-tend to be members of a union, with collectively negotiated salary increases, and their salary data were unavailable to us.

Of course, a crucial element in our study is the definition of "performance." School districts and their school board members are idiosyncratic and evaluate superintendents' performance in a wide variety of ways; our methodology, in contrast, is to focus on a few well-defined outcomes. Specifically, we assume that school districts value high educational performance and low school tax rates, each relative to the comparable outcome in similar school districts in the state. ${ }^{3}$

\footnotetext{
${ }^{2}$ None of the previous studies (see Ehrenberg, Chaykowski, and Ehrenberg 1986 for citations) attempted to measure "performance" and to see if it matters. Indeed, March and March (1977) argued that the mobility of superintendents is almost a random process. Their approach, however, was criticized by Schmittlein and Morrison (1981).

${ }^{3}$ A district can simultaneously have high test scores and low tax rates if the district's administrators efficiently manage both financial and educational
}

\section{Preliminary Analysis 4}

Our analysis utilizes data on the more than 700 school districts in New York State during the 1978-79 to 1982-83 period obtained from the New York State Education Department's "Basic Educational Data System" (BEDS) annual school district tapes. Unfortunately, no data on nonsalary compensation items are available on the BEDS tapes, so we can analyze only salaries rather than total compensa. tion. Excluded from the sample each year were New York City (which, because of the size of its school system and the large number of its local district school boards, is not comparable to any other district in the state), districts in which the superintendent's position was vacant, and districts that failed to report salary information.

The mean salary of superintendents in the sample rose from slightly under $\$ 95,000$ in $1978-79$ to over $\$ 44,000$ in 1982-83. Each year the variation in salaries across districts was large; for example, in 1982-83 superintendents in the sample earned between $\$ 20,000$ and $\$ 71,000$, and the standard deviation in salaries was $\$ 10,000$. Although much of this variation is clearly due to the wide variation of school district sizes in the sample, we demonstrate below that other factors are also important.

The BEDS data permit us to determine if a superintendent remained in the same school district for two consecutive years, moved from one district to another in the state during the period, or moved from a school district in the state to "out of sample" status. In the last case, the superintendent may have retired or died, moved to another superintendency outside New York State (though previous studies suggest that the vast majority of school superintendents serve in only on: state during their lifetime), moved to a different educational position (nonsuperin-

resources and effectively motivate school district personnel.

tTables of descriptive statistics on superinten. dents' salaries and mobility during the period are available in Ehrenherg, Chaykowski, and Ehrenberg (1986). 
tendent') in another district in the state, or switched to a noneducational position-or his school district may simply have failed to report data in the second year.

The data suggest that the annual turnover rates of school superintendents were only 12 to 19 percent. Each year only 4 to 6 percent of the superintendents moved to another district in the state, and 8 to 13 percent dropped out of the sample. Below, using multinomial logit analysis, we attempt to explain the determinants of the mover/stayer status of superintendents each year.

Aside from school district performance, what forces might be expected to influence a superintendent's salary? Some of the possible factors that come to mind are chatracteristics of the school district: larger districts (where a superintendent's job is more difficult), wealthier districts (where the demand for education is likely to be greater), districts containing a bigh proportion of highly educated adults (who are likely to have a strong "taste" for education), and districts with students who have special educationil needs (such as those with a large proportion of minority students) are all likely to pay higher salaries in an effort to attract and retain high. quality superintendents. Other possible factors are characteristics of the superintendent: it is reasonable to expect more experienced and more highly educated superintendents to command higher salaries. Table 1 contains descriptions of the variables we use to capture these and other characteristics that are hypothesized to influence superintendents' salaries.

Table 2 reports estimates of annual cross-section salary equations of the form

$$
\text { (1) } \log \left(W_{i}\right)=a_{0}+a_{1} X_{i}+a_{2} s_{i}+\epsilon_{i} \text {, }
$$

where $W$ is the annual salary of the superintendent, $X$ is a vector of school district characteristics, $S$ is a vector of

Table 1. Variable Descriptions.

\begin{tabular}{|c|c|}
\hline Variable & $\overrightarrow{D e s c r i p t i o n}$ \\
\hline LENR & Logarithm of total enrollment in the district in the year. \\
\hline I,VAL. & Logarithm of the fulls value of property in the district per enrotted student, in the year. \\
\hline LYl & Logarithm of per capita personal income in the county in the year. \\
\hline LY2 & Logarithm of nedian fumily income in the district in 1979. \\
\hline PNW & 1979 percentage of the district's population that was nonwhite. \\
\hline PHED & 1979 percentage of the district's adult population with greater thatı a bachelor's degree. \\
\hline PCHL & 1979 percentage of the district's households with children at home. \\
\hline POOC & 1979 percentage owner-occupied housing in the district. \\
\hline PCOL & 1979 percentaye of the district's adult population with some college or a bachelor's degree. \\
\hline PURB & 1979 percentage of the district's population residing in urban areas. \\
\hline DDEG & 1 = superintendent had a doctoral degree in the year; $0=$ no such degree. \\
\hline CDEC & $1=$ superintendent had a certificate of advanced study in the year; $0=$ no such degree. \\
\hline EXPS & Superintendent's total number of years' experience in other school districls as a superintendent. \\
\hline TEN & Superintendent's years of tenure in the current district. \\
\hline EXPG & Supurintendent's years since receiving a bachelor's degree. \\
\hline
\end{tabular}

Sources:

(1) SAL, LENR, LVAL-New York State Education Department, "Basic Educational Data System" (BEDS) School District Tapes for 1978-79 to 1982-89; and New York State Education Department, "Financial Data System" (ST3) School District Tapes for 1978-79 10 1982-83.

(2) LYI-U.S. Department of Commerce, Bureau of Economic Analysis, unpublished tabulations for 1978 to 1982.

(3) L.Y2 to PURB-U.S. Bureau of the Census, 1980 Census of Poputation, Schrol District Data File for New York State.

(4) DDEG 10 EXPG-American Association of School Administrators, Who's Who in Educational Administration, 1976-77, 1980-81 editions; and the survey of school superintendents in New York State conducted by the au. thors in the summer of 1985 . 
Table 2. Determinaints of School Superintendent:' Salaries in New York State:

Annual Cross-Sections.

(absolute values of $t$ statistics in Farentheses)

\begin{tabular}{|c|c|c|c|c|c|}
\hline \multirow[b]{2}{*}{ Variable } & \multicolumn{5}{|c|}{ Logarithen of Antutal Salary (SAL) } \\
\hline & $1978-79$ & $1979-80$ & $1980-81$ & $1981-82$ & $1982-83$ \\
\hline LENR & $.127(22.5)^{*}$ & $.113(20.0)^{*}$ & $.117(21.2 *$ & .111 $(20.7)^{*}$ & $.110(20.0)^{*}$ \\
\hline LVAL & $.045 \quad(5.8)^{*}$ & $.025(4.1)^{*}$ & $.028 \quad\left(4.8 ?^{*}\right.$ & $.019 \quad(3.9)^{*}$ & $.011 \quad(2.3)^{*}$ \\
\hline L.YI & $.191 \quad(5.2)^{*}$ & $.228 \quad(6.5)^{*}$ & $.228 \quad(6.3)$ & $.273 \quad(8.4)^{4}$ & $.294(9.8)^{*}$ \\
\hline $1 Y 2$ & $.151 \quad(3.6)^{*}$ & $.146(3.4)^{*}$ & $.189 \quad(4.8)^{4}$ & $.152 \quad(9.6)^{*}$ & $.120(2.9)^{*}$ \\
\hline PNW & $.178(2.6)^{*}$ & $.072 \quad(1.2)$ & $.032 \quad(0.4)$ & $-.071 \quad(1.0)$ & $-.111 \quad(1.7)$ \\
\hline PHED & $.357(2.5)^{*}$ & $.449(3.0)^{*}$ & $.367 \quad(2.5)^{\prime 4}$ & $.445 \quad(3.1)^{*}$ & $.494 \quad(3.4)^{*}$ \\
\hline PCHL & $.200(2.0)^{*}$ & $.009 \quad(0.0)$ & $.087 \quad(0.9 ;$ & $-.001 \quad(0.0)$ & $.074 \quad(0.8)$ \\
\hline POOC & $-.073 \quad(1.0)$ & $.022 \quad(0.3)$ & $-.049(0.7)$ & $-.036 \quad(0.5)$ & $-.080 \quad(1.0)$ \\
\hline PCOL & $.185 \quad(1.8)$ & $-.147 \quad(1.3)$ & $.105 \quad(1.1)$ & $.224 \quad(2.2)^{*}$ & $.218(2.1)^{*}$ \\
\hline PURD & $.014 \quad(1.0)$ & $.025 \quad(1.6)$ & $.000 \quad(0.0)$ & $-.019 \quad(1.9)$ & $-.012 \quad(0.9)$ \\
\hline DDEG & $-.008 \quad(0.7)$ & $.006 \quad(0.6)$ & $.010 \quad(1.0)$ & $.013 \quad(1.4)$ & $.023 \quad(2.3)^{*}$ \\
\hline CDEG & $.000 \quad(0.0)$ & $-.016 \quad(1.4)$ & $-.014 \quad(1.3)$ & $-.032 \quad(3.1)^{*}$ & $-.016 \quad(1.7)$ \\
\hline EXPS & .002 (1.1) & $-.000 \quad(0.3)$ & $.001 \quad(0.6)$ & $-.000 \quad(0.1)$ & $-.000 \quad(0.2)$ \\
\hline TEN & $.006 \quad(5.9)^{*}$ & $.006 \quad(5.0)^{*}$ & $.006(5.5)^{\mathrm{n}}$ & $.004 \quad(3.6)^{*}$ & $.007(5.7)^{*}$ \\
\hline EXPG & $.002(2.1)^{*}$ & $.003 \quad(3.3)^{*}$ & $.002(2.1)^{n}$ & $.002 \quad(2.2)^{*}$ & $.00] \quad(0.8)$ \\
\hline $\mathrm{k}^{2}$ & .842 & .845 & .840 & 896 & .828 \\
\hline N & 590 & 557 & 558 & 570 & 574 \\
\hline
\end{tabular}

${ }^{2}$ Also included were an intercept term and dummy variables for nonreporting of the superintendents' previous experience, current job tenure, and year of bachelor's degree. Experience and job tenure were available for 35 to $6 \%$ of the sample each year, and years since degree was l! pically available for 70 to $80 \%$ of the sample.

* Statistically significant at the .05 level (two-tailed test).

characteristics of the superintendent, and $\epsilon$ is a random error term. ${ }^{5}$

As noted in Table I, the school district data used in the analysis come from a variety of federal and state sources. The characteristics of the superintendents are taken from two volumes of Who's Who in Educational Administration, the directory of members of the American Association of School Administrators, and the responses to a survey of all school superintendents employed in New York State in 1984-85 that was conducted by the authors in late May to early July of 1985 . Because fewer than hall of the superintendents in the sample belonged to the professional association and the response rate of incum-

\footnotetext{
${ }^{5}$ If school district "performance" does influence superintendents' snlary levels, estimation of equation (I). which omits performance, will yield biased coefficients unless the performance measures are uncorrelated with the variables included in (1). As will become clear, we have constructed performance meastures that are uncorrelated with the variables in (j).
}

bents in 1984-85 to the survey was about 70 percent, many observations lacked data on some: or all of the superintendents' characteristics. Furthermore, we could not obtain school district data for some of the districts. The exclusion from the sample of observations for which either the school district's characteristics or the superintendent's degree information was missing reduced the sample sizes to between $\mathbf{5 5 0}$ and 600 observations each year.

As expected, the characteristics of school districts prove to be important determinants of superintendents' salaries. Ceteris paribus, in each year, larger districts (as measurelt by the logarithm of total enrollment, LENR), wealthier districts (as measured by the logarithms of property values per enrolled student [LvaL], per capita personal income in the county [Lr1], or census year 1979 median family income in the schoos] district [LY2]), and districts that place a high value on education (as measured by the percentage of the district's aclult population with education 
beyond a bachelor's degree, PHIED) all are associated with higher stuperintendents' salaries. ${ }^{6}$

In conirast, only two of the superintendents ${ }^{2}$ characteristics-years of tenure in the current district (TEN) and years sirce receiving a bachelor's degree (EXPG) (a rough proxy for age or total labor market experience)-prove to be statistically sig. nificant. ${ }^{7}$ Moreover, quantitatively the efferts of these variables are very small, with the rate of return per year of tenure being roughly 0.6 percent and that per year since degree being roughly 0.2 percent. Somewhat surprisingly, neither the possession of a doctorate degree (DDEC) or a certificate of advanced study in administration (CDEC)-the latter an intermediate degree between a masters and a doctorate-nor the total number of years of previous experience as a superintendent in other school districts (EXPs) is systematically associated with salary.

A widely accepted generalization about the mobility of superintendents, and one supported by the results of our survey, is that they typically move (at least during the early stages of their careers) from smaller to larger and froind poorer to wealthier districts. It may be, therefore, that personal characteristics affect salary indirectly by influencing the characteristics of the school district in which the superintendent is located, rather than directly by influencing salary decisions within a district.

To test this hypothesis, the logarithm of property value per enrolled student and the logarithm of total enrollment in the superintendent's district were both regressed each year on the personal characteristics of the superintendent (excluding years of tenure in the current district). The results (see Ehrenberg, Chaykowski, and Ehrenberg 1986) suggest that having

\footnotetext{
'Bosh median family income in the sehool district and per capita income in the county were included as explanatory variables here (and in parts of the analysis below) because the former was available only in the census year.

7 We say "his" throughout because over 97 percent of the approximately 1,010 stiperintendents in our sangle were men.
}

a doctorate, having more prior experience as a superintendent in other districts, and being older all were associated with employment in larger school districts, and having a doctorate was also associated with being employed in wealtitier districts.

These findings have important implications for the analysis that follows of the relationship between superintendents' compensation and school districts' performance. Even if, within a given school district, no relationship is found between a superintendent's compensation and his school district's performance, superintendents might still be rewarded for district performance by increased opportunities for mobility to better-paying positions.

\section{Evaluating the Performance of School Distuicts}

We assume in this study that school hoards value high academic test scores (high educational output) and low school tax rates (more money available for other public and private uses), each relative to the comparable outcome in similar school districts in the state, and that they evaluate a superintendent (at least implicity) by his or her district's performance on these criteria. It is natural to ask how these measures correspond to the criteria that superintendents believe school boards actually use in their evaluation. To answer this question, the survey of school superintendents that we conducted asked the respondents to list the criteria they believed their school boards used in their evaluation. Although we gave keeping test scores high and tax rates low as two examples of criteria that might be used (as well as "maintaining good relations with the board"), the question we asked was open-ended. Eacli respondent was also asked to attach to the survey form a copy of the formal evaluation instrument in effect at the time of the survey, if there was one. Eighty percent (397) of the 496 respondents to our survey included a list of criteria in their response, and about 22 percent (86) of those 397 attached formal evaluation instruntents.

We assigned the criteria mentioned by 
superintendents to twelve broad classifications and made a count of responses under each classification (Table 3). Since most superintendents mentioned more than one criterion, the total count across categories far exceeds the number of respondents.

Perhaps the most striking result, given that keeping test scores high and tax rates low were two of the only three examples provided for this item on the questionnaire, is that the most commonly men. tioned criteria were community/public relations and school board relations. Fiscal management (the category that would include, but is not limited to, keeping tax rates low) came in fourth on the list and was mentioned by about two-thirds of the respondents. Academic performance and achievement (the category in which keeping test scores high would fall) was eighth on the list and was mentioned by fewer than one-third of the respondents.

What are the implications of these

Table 3. New York State Public School Superintendents' Perceptions of the Criteria School Boards Use in Evaluating Their Performance.

\begin{tabular}{lr}
\hline Response & Numler \\
\hline Mentioned that Criteria Included: & \\
Community/Public Relations & 318 \\
School Board Relations & 294 \\
Staff and Personnel Management & $\mathbf{2 8 7}$ \\
Fiscal Management & $\mathbf{2 6 7}$ \\
Curriculum Development, Educational & \\
Planning and Leadership & 202 \\
Professional and Personal Development & 132 \\
General Managgement and Administration & 129 \\
Academic Performance and Achievement & 125 \\
Facilities Manigement & 50 \\
Student Services and Relations & 49 \\
Student Discipline & 26 \\
Parent Relations & 25 \\
Included a Formal Evaluation Instrument & 86
\end{tabular}

Source: survey sent by the authors to approximately 700 school superintendents in New York State (excluding New York City) in May to July. 1985. 496 superintendents responded to the survey. and of that number, 397 responded to the question on criteria used in evaluating superintendents' performance. Response rates did not vary substantially across size -lasses of school districts. findings for the use of the objective performance measures that we propose? On the one hand, it is hard to think of readily a.vailable objective neasures for most of the categories of criteria mentioned by respondents; measures of fiscal management and academic performance and achievement may be the best one can do. On the other hand, the questionnaire results clearly indicate that the two measures we use as indicators of how superin. tendents are evaluated in compensation decisions are measured with error; if the errors are random, the coefficients of our performance variables will be biased toward zero in the mobility and compensation change equations. Furthermore, given that more than twice as many respondents mentioned fiscal management as did academic performance, one might expect that, on average, the former will prove to be more important than the latter in explaining compensation and mobility.

To show how the performance measures were constructed, in Table 4 we present estimates of tax rate and educational outcome equations for 1979-80. (Separate equations were estimated for each year and the results are very similar across ytars.) The tax rate variable is the logarithrn of the full-value property tax rate in the school district (total school district property tax revenue divided by total value of taxable property in the school district). The educational outcome variables are the logarithms of the percentage of the district's students who fall below the state reference point on a standard. ized sixth grade mathematics examination and the average percentage who fall below the state reference point on standardized third and sixth grade reading and mathematics examinations. ${ }^{8}$ Students who fall below the state reference point are deemed

\footnotetext{
We isolate the sixth grade mathematics lest because it was the only one of the four tests that did not underyo revision during the period and that was given in all tive years. As a result, although the entire battery of tests can be used to construct a performance measure when analyzing a single year's cross-section, the longitudinal analyses in this paper. which pool data across years, are restricted to using the single sixth grade mathematics test.
} 
Table 4. 1979-80 Tax Rate and Educational Outcome Rquations. (absolute values of $t$ statistics in parentheses)

\begin{tabular}{|c|c|c|c|}
\hline Variable & $\log (D)$ & $\log (C M)$ & $\log (A S)$ \\
\hline $\begin{array}{l}\text { LVAL } \\
\text { LYI } \\
\text { LYY } \\
\text { PNW } \\
\text { PHED } \\
\text { PCHL } \\
\text { POOC } \\
\text { PCOL } \\
\text { PURB } \\
\text { D }\end{array}$ & $\begin{array}{c}-.100(7.0)^{* 4} \\
-.001(0.0) \\
.180(1.8)^{*} \\
.691(4.6)^{* *} \\
1.009(2.8)^{* 4} \\
.979(3.7)^{* 4} \\
-.417(2.1)^{* 4} \\
.988(1.4) \\
.271(3.6)^{* *} \\
.006(0.1)\end{array}$ & $\begin{array}{c}-.036(1.2) \\
-.243(1.3) \\
-.253(1.2) \\
1.351(4.2)^{* *} \\
-1.391(1.8)^{*} \\
.670(1.2) \\
-.689(1.7)^{*} \\
-.685(1.2) \\
-.042(0.6) \\
.278(2.9)^{*}\end{array}$ & $\begin{array}{r}-.098(1.6) \\
-.029(0.2) \\
-.397(2.8)^{* *} \\
1.111(5.2)^{* *} \\
-1.801(9.5)^{*} \\
.374(1.0) \\
-.653(9.9)^{* *} \\
-.634(1.7)^{*} \\
-.009(0.2) \\
.205(3.1)^{* *}\end{array}$ \\
\hline $\begin{array}{l}\mathrm{k}^{2} \\
\mathrm{~N}\end{array}$ & $\begin{array}{r}.457 \\
573 \\
\end{array}$ & $\begin{array}{r}.184 \\
565\end{array}$ & $\begin{array}{r}.949 \\
568\end{array}$ \\
\hline \multicolumn{4}{|c|}{ 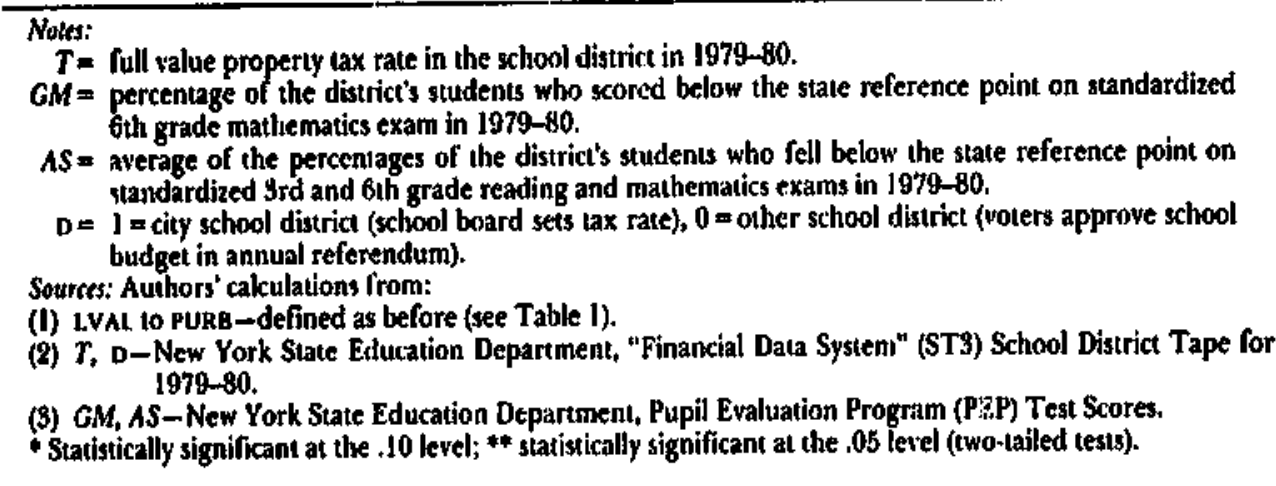 } \\
\hline
\end{tabular}

to require remedial services, and state aid is increased to help fund these services. Since these outcome scores measure the proportion who "fail" these tests, we are focusing on the bottom tail of the academic achievement distribution."

For each of these three outcomes $(O)$, equations were estimated of the form

These tests, unfortunately, were the only ones for which the New York Siate Education Department could give us data, since they are the only tests that all students in the state are required to take. It obviously would have been preferable to lave test scores for older students and also to focus some attention on the upper tail of the achievement distribution. For example, data on high school graduation rates, or on the fraction of seniors going on to higher education, would have been desirablc. Our focus on the lower tail of the elementary school student test distribution imparts additional error to our educational performance measures, as does the omission of other aspecis of educational perfor. mance that are not easily measured (such as leaching students to write, or giving them a sense of social responsibitity).

$$
\log O_{j}=\underset{j=1,2,3}{b_{0 j}+b_{1 j} Z+u_{j}}
$$

where $Z$ is a vector of school district characteristics expected to influence these outcomes and $u$ is a random error term. In fact, the variables in (2) are assumed to be identical to those school district variables that enter the salary equation, save that a $(1,0)$ "city school district" dummy variable replaces the continuous variable for district size. The dummy variable is included because in the large city school districts in New York State the property tax rate is set by an elected school board (subject to constitutional limitations), whereas in the smaller school districts the school budget, and hence the tax rate, is set each year by a voter referendum. One might conjecture that in the latter situation, ceteris paribus, direct voter control will lead to lower tax rates.

In the main, the estimates in Table 4 conform to our expectations and provide 
reasonable explanations of the tax rates and test scores. For example, with respect to tax rates, although wealthier districts (as indicated by LVAL) have lower tax rates, since the elasticity of the tax rate with respect to per capita property values is greater than minus one, they raise more revenue to finance education. Similarly, higher tax rates are found in districts that are relatively well off in terms of current income (LY2); districts with high proportions of nonwhites (PNW), and thus special needs; districts with high proportions of adults with more than a bachelor's degree (PHED), who presumably have a taste for education; and districts in which a relatively high percentage of households have children at home (PCHL), and where spending on education is thus valued more highly relative to keeping taxes down. ${ }^{10}$

Similarly, wealthy districts, districts witly high current income, and districts with highly educated adults, ceteris paribus, all have lower failure rates on the academic tests than other districts, and districts with a higher proportion of nonwhites have higher failure rates. Failure rates, but not tax rates, also appear to be higher in the "city" school districts. It is worth noting that the equation used to predict the average test failure rate "fits" much better than the equation used to predict the sixth grade math test failure rate. Although it would be preferable to use the former in our analysis, only the latter can be used in an analysis that exploits the longitudinal nature of the data (see foolnote 9, above).

Given these estimated cuefficients (cor-

\footnotetext{
${ }^{10} \mathrm{~A}$ number of people have poinied out to us that in many communities businesses pay a substantial share of property taxes. Since only residents vote on school taxes, it would be desirable to include the share of property owned by residents in the total tax base as an additional explanatory variable in the tax vate equation. Our talks with officials in the New York State Education Department and Division of Equalization and Assessment indicate that (l) residen. nial property datn are not available at the school district level in New York State and (2) such data would not capture what we are after anyway, since some business property may be owned by residents and some residential (rental) property may be owsed by nonresidents.
}

responding to $\hat{b}_{0 j}$ and $\hat{b}_{1 j}$ in equation 2 ), one can obtain estimated values of the logarithm of each outcome for each school district (i) from

$$
\widehat{\log } O_{j i}=\begin{gathered}
b_{0 j}+b_{1 j} Z_{i} \\
j=1,2, \ldots 3 .
\end{gathered}
$$

The school district's performance is then defined as the difference between the predicted and actual values of the log of each outcome."

$$
P_{j i}=\underset{j=g}{ } O_{j i}-\log O_{j i}
$$

Positive values of $P_{j i}$ indicate positive performance for the district, since positive values would occur only when predicted tax rates (or predicted failure rates on tests) exceed actual tax rates (or actual failurs: rates on tests) in the school district.

It is worth reemphasizing that equations (2), (3), and (4) are estimated separately each year. Thus, the structural equations that yenerate the performance measures are allowed to vary across years, as are the estimates of tax and test score performance in the district.

\section{School District Performance and Superintendent Mobility}

As noted above, each year approximately 5 percent of the sample moved to another school district in New York State. Of those, about 80 percent received salary increases and 20 percent either received the same salary or suffered salary cuts. Thus, in each year four mobility categories are observed: about 85 percent of the superintendents continued in the positions they held the previous year, about 4 percent moved to another New York State school district and received a highe: salary, about 1 percent moved to another

\footnotetext{
"A similar "residual approach" to estimating performance was used in Goldstein and Ehrenberg (1976) in a different cuntext, It is a property of ordinary least squares that the computed residuas are uncorrelated with the explanatory variables in (2). Since these variables are identical to those found in the cross-section salary equation (equation 1), omission of the performance measures from (1) will not bias any of the other coefficients in that equation.
} 
New York State school district and received either the same salary they had before or a reduced salary, and about 10 percent dropped out of the sample. What factors determine in which of the four classes a superintendent wound up in each year?

To econometrically model this joint wage change-job change-sample exit process would be extraordinarily complex, since both school boards and superintendents are involved in the relevant decision process. The ideal procedure would be to estimate a complete structural "matching model" that contains both employer (school board) and employes (school superintendent) decision rules. Given the limited data we have, however, we instead estimated simpler reduced form models of the form

$$
\begin{aligned}
\log \left(\frac{P(\text { state }:=j)}{P(\text { state }=4)}\right)= & d_{0 j}+d_{1 j} X \\
& +d_{2 j} s+d_{g j} T \\
& +d_{4 j} E+\epsilon_{j} \\
& j=1,2,3
\end{aligned}
$$

where $Y$ is a vector of characieristics of the school district (a subset of the $X$ in equation 1), $S$ is the vector of superintendent characteristics, and $T$ and $E$ are the relevant tax rate and educational tesi score performance measures. The notation $P($ state $=j)$ denotes the probability that an individual is in state, with the four states being continuing in the same district, moving to a new district with a salary increase, moving to a new district with the same or a lower salary, and exiting from the sample. Under suitable assumptions about the distribution of the error terms (i.e., that it is logistic), the system in equation (5) represents a mulinomial logit model and can be estimated by standard maximum likelihood meth. ods.

What are the relevant tax rate and educational test score performance nieasures to use in this analysis? On the one hand, one might argue that the relevant measures would involve changes in performance over time. That is, a superintendent's mobility probabilities might be influenced by whether his school district's tax rate and test score performance measures had improved or worsened over time. On the cther hand, one might argue that keeping test score and tax rate performance at a constant but high (low) level might lead to higher probabilities of moving to a higher- (lower-) paying job. We investigate the empirical question of whether a change in performance measure or a level of performance measure is more useful by experimenting with various specifications.

If measures of performance level are used, it is important to recognize that data on performance in one district are not always immediately available to other districts for comparative purposes for use in hiring and firing and compensation decisions. For example, suppose we are looking at potential mobility between 1979-80 (the base year) and 1980-81 (the new year). The base year math test (for 1979-80) was given in the spring of 1980 , and a district may have received its own test results back shortly thereafter. There is little chance, however, that it received data on the test scores in other districts in the state before the beginning of the next academic year (the fall of 1980). Such information would thus come too late to be used to estimate test score performance indexes that could then be used in the decision to: tain the superintendent for 1980-81 or to try to attract a superintendent from a districe that had a higher test score performance index. Thus, the pertinent test score performance measure in a study of superintendent mobility between $1979-80$ and $1980-81$ is that for $1978-79$. Below, we refer to this measure as the lagged year district test performance index.

Unlike comparative data on academic tests, comparative data on base year tax level performance are potentially available to be used in personnel decisions affecting superintendents. But even so, if the processing of such information by the decision-making body is sufficiently delayed, a lagged year tax rate performance index may again be the relevant one to use.

Table 5 presents the estimates of the specification of equation (5) that uses the 
Table 5. Determinants of Superintendents' Mobility: Multinorrial Logit Analysis." (absolute values of $\mathrm{t}$ statistics in parentheses!

\begin{tabular}{|c|c|c|c|}
\hline Variable & $\frac{P(\text { mote, } S>0)}{P(\text { stoy })}$ & $\frac{P(\text { move, } S \leq 0)}{P(\sin y)}$ & $\frac{P \text { (leave sample) }}{P \text { (stay) }}$ \\
\hline c & $45.263(4.2)^{*}$ & $19.167(1.0)$ & $-5.494(1.3)$ \\
\hline Y9] & $.645(1.8)$ & $.071(0.1)$ & $.530(2.3)^{*}$ \\
\hline Yด2 & $-1.670(2.8)^{*}$ & $.149(0.2)$ & $.054(0.2)$ \\
\hline MPL & $-.12 B(0.4)$ & $-.448(0.8)$ & $-.255(1.1)$ \\
\hline TPL. & $1.466(2.0)^{*}$ & $-2.006(1.7)$ & $-.176(0.4)$ \\
\hline CDEG & $.050(0.1)$ & $-.029(0.0)$ & $-.194(0.4)$ \\
\hline DDEG & $1.307(9.0)^{*}$ & $.586(0.9)$ & $.368(1,3)$ \\
\hline EXPG & $-.062(1.9)$ & $-.049(0.8)$ & $-.089(9.8)^{*}$ \\
\hline TEN & $-.014(0.2)$ & .075 (1.1) & $-.004(0.1)$ \\
\hline Exps & $.121(3.0)^{*}$ & $.144(9.2)^{*}$ & $-.086(0.7)$ \\
\hline LENR & $-.009(0.3)$ & $.039(0.1)$ & $.037(0.8)$ \\
\hline LVAl. & $-.202(0.7)$ & $.164(0.8)$ & $-.164(1.1)$ \\
\hline 142 & $-4.637(3.9)^{*}$ & $-1.927(1.4)$ &. $.254(0.5)$ \\
\hline
\end{tabular}

"Also included in the analysis were dunımy variables for nonreporting of age, tenure at base year job, and experience as a superintendent on previous jous.

Number of superintendents in different mobility categories:

$\begin{array}{lr}\text { Total Observations } & 1,408 \\ \text { Stay } & 1,207 \\ \text { Move, } \$>0 & 46 \\ \text { Move, S } \leq 0 & 19 \\ \text { Leave Simple } & 196\end{array}$

Variable definitions: For most varjables, see Table 1. MPL: School district math test performance measure in the lagged year in the superintendent's bise year school district. TPL: School district tax rate performance measure in the lagged year in the superintend ant's base year school districl.

* Statistically significant at the .05 level.

lagged year performance level measures (TPL for tax rate performance, MPL for math test score performance). One striking result is that the lagged tax level performance measure (TPL) is positively associated with the odds of moving to a higher-paying job (relative to staying) and negatively associated with the odds of moving to a lower-paying job (relative to staying). Put another way, among movers the better the lagged tax level performance is, the more likely the individual will move to a better job. Thus, it appears that a school district's financial performance does affect its school superintendent's future.

The math performance variable (MPL), in contrast, is always insignificant. The poor predictive power of that variable in comparison with the tax level performance variable is consistent with the questionnaire results described above.

As suggested by the cross-section results discussed above (under "Preliminary Analysis"), having a doctorate degree (CDEG) increases a superintendent's chances of moving to a better-paying job relative to his chances of not moving. Older superintendents, as measured by years since receiving a bachelor's degree (EXPG), are less likely to move to another job and more likely to leave the sample (again, relative to staying in the same district)findings that clearly reflect the decline of voluntary mobility and increase in retirement rates with age. Previous experience as a superintendent in other districts (EXPS) is positively associated with moves to both higher-paying and lower-paying jobs, relative to staying in the same district, a result that may well reflect heterogeneity of turnover probabilities. (See Chamberlain 1981 or Heckman 1981 for discussion of methods to distinguish heterogeneity bias from other factors.) Finally, employment in a school district with high median family income is associated with a reduced probability of moving to a higher-paying job relative to the probability of staying. As indicated in Table 1, higher-income school districts pay more than other school 
districts, thereby reducing the likely gain from mobility.

The last-mentioned result raises the question of whether some measure of the superintendent's potential gain from mobility should be directly included in these equations. We experimented with four such measures: the logarithm of the superintendent's base year salary, the residual from a base year log salary equation that included only superinten. dents' characteristics, the residual from a hase year log salary equation that included both superintendionts' and school district characteristics, and the residual from a comprehensive base year log salary equation that also included performance measures. None of these measures, however, proved to be statistically significant (when they were included one at a time), nor did their inclusion affect the pattern of signs and significance of the coefficients in Table 5.

We also tested for the sensitivity of our mobility results to the specification of the performance variables. Four specifications were tested: base year level, lagged year level, both base and lagged ycar levels, and change between the base and new year. The results (see Ehrenberg, Chaykowski, and Ehrenberg 1986) indicate quite clearly that only the lagged level of tax performance is significant, with better performance leading to an increased (decreased) probability of moving to a position with a salary higher than (equal to or lower than) the base year salary, relative to the probability of remaining on the same job.

\section{School District Performance and Superintendent Salary Changes}

In this section we examine the question of how salary increases - both for superintendents who remain in the same district for two consecutive years and for those who move to another district in New York State--are related to the lagged year tax rate and test score performance measure in the base year school district. ${ }^{12}$

\footnotetext{
${ }^{18}$ Treating mobility at exogenous here leads to obvious potential selectivity problems: we may be
}

Table 6 presents estimates of tro salary change equations for superintendents who remained in the sample over two consecutive years. Column (1) presents the simplest model, in which salary change is postulated to be a function only of year dummy variables and a dichotomous variable (M) for whether the superintendent changed jobs $(1=$ yes, $0=$ no $)$ during the period. The results in this column suggest that mobility mattered; on average, superintendents who changed jobs received salary increases that were 6 percent higher than those who remained in the same position. It does not follow, however, that mobility always pays. In fact, as noted above, approximately one-fifth of the movers each year failed to increase their salaries; some of these suffered salary losses as large as 30 percent.

Column (2) presents the results of estimating a model in which a superintendent's salary change is also postulated to be a function of the lagged tax rate and math test score performance measures in the superintendent's base year school district, as well as the differences between the base year district and new year district in the logarithms of county incone, school district enroliment, and school district full value of property per student. (For stay. ers, the values calculated are simply the within-district changes in the varjables between the base and new years.) The coefficients of each of these change variables and the performance measures were allowed to differ between mover: and stayers in this model.

The major result of this specification is the finding that, ceteris paribus, movers suffer salary losses in the range of 5 to 6

confounding the effect of the performance variables on motility prospects with their effects on salary cluanges given mobility status. But in the alssence of a well-specified structural model of the mobility process thint takes account of both school board and superintendent decision rules (see the discussion headed "School District Performance and Superintendent Mobility," above), any attempt to use the estimates in Table 5 to obtain a Heckman (1979)-type "selectivity correction" term to add to the mobility equations would be ad hoc at best and subject to specification error. We do nol attempt such correc. tions herc. 
Table 6. Salary Cliange Equations for Superintendents Who Stayed in the Same Position or Moved to Another Position in New York State.

(absolute values of $\mathbf{t}$ statistics in parentheses)

\begin{tabular}{|c|c|c|c|}
\hline Variable & (I) & (2) & \\
\hline c & $.061(37.9)^{*}$ & .079 & $(8.7)^{*}$ \\
\hline Y81 & $.020 \quad(7.3)^{*}$ & .010 & $(3.0)^{*}$ \\
\hline Y82 & $.006 \quad(2.3)^{*}$ & -.004 & $(0.8)$ \\
\hline M & $.060(10.0)^{*}$ & -.055 & $(4.4)^{*}$ \\
\hline$\Delta L Y_{1}$ & & -.110 & (J.4) \\
\hline SI.ENR & & -.004 & $(0.1)$ \\
\hline SLVAL & & .003 & $(0.5)$ \\
\hline MPL. & & .007 & $(2.5)^{*}$ \\
\hline TPL & & .008 & (1.3) \\
\hline MoLYl & & .425 & $(5.0)^{*}$ \\
\hline M•ALENR & & .105 & $(2.6)^{*}$ \\
\hline M*ALVAL & & .052 & $(4.1)^{*}$ \\
\hline MAMPL & & $-.038^{a}$ & $(2.8)^{*}$ \\
\hline $\mathrm{M} * \mathrm{TP}$. & & $.067^{\circ}$ & $(2.2)^{*}$ \\
\hline $\mathbf{N}$ & 2,208 & 1,210 & \\
\hline $\mathbf{R}^{2}$ & .066 & .322 & \\
\hline
\end{tabular}

"Implied marginal effects of lagged year performance rariables on movers' salary changes: $\mathrm{TP}_{\mathrm{L}}-.075(2.5), \mathrm{NP}_{\mathrm{L}}-.032(2.5)$.

Explastatious:

$Y B I$ Duminy sariable equal to one if the $1980-8 \mathrm{I}$ and $198 \mathrm{I}-82$ observations dif. fered, zero otherwise.

Yog Duminy variable equal to one if the 198|-82 and 1982-83 observalions differed, zero othertise.

M Dutnmy variable equal to one if the superintendent moved to another su. perintendency in New York Siate, zero if he remained in the same sclsool dis. tuicl.

sLy The logarithm of per capita personal income in the county in whicl the superintendent's school district was to. cated in the new year minus the log. arithm of per capita personal income in the county in which lis school tlistrict was localed in the base year.

A1.r.Nk The logarithm of total enrollment in the superintendent's school district in the new year minus the logarithon of total enrollment in his school district in the base year.

sly AL. The lognrithm of the full value of prop. erty per enrolled student in the superincendent's school district in the new year minus une logarithn of the full value of property per emrolled student in bis school clistrict in the base vear.

N1'L, TPl. Mall test and tas rate perfornance measures in the lagged year in the superintendent's base rear school district.

* Statistically significant at the .05 level (1tio-tailed (est). percent relative to stayers. Changes in these variables, hoivever, are positively associated with salary changes for movers but not for stayers. Hence, in order for superintendents to gain from mobility, they must move to either higher-income, larger, or wealthier school districts. This result is fully consistent with the crosssection salary equations presented in $\mathrm{Ta}$. ble 2.

The coefficient on the lagged math test performance variable suggests that superintendents who are "stayers" in school districts wit: above-average math test performance receive larger salary in. creases than other superintendents who do not change jobs. Tax rate performance appears also to be positively associated with the salary increases of stayers, but the coefficient on that variable is not significant.

The evidence on the effects of performance on the salary changes of superintendents who clrange jobs is a bit more mixed. The derived estimates (from the stayer and interaction coefficients) of the effects of performance on movers' salary changes are found in the note to the table. Although lagged tax performance in the base year school district is positively associated with earnings gains for superin. tendents who change jobs, the assoriation with lagged math test performance is negative. We have no explanation for the latter finding, which conflicts wilh the other results reported here and in the previous section. ${ }^{13}$

\section{Superintendents' Influence on School District Performance}

Two presumptions of our paptr are that school superintendents can affect our measures of school district perforinance

is As in the previous section, inclusion of the superintendent's salary in the base year as an additional explanalory variable did not alter any of the other cosfficients. For the subset of school districts for which we had teacher salary data, we also attempied to test if school superintendents' salary clanges were related to the salary rhanges of teacliers in their school districl. This tariable, however, neter proved statistically significant. 
and that the provision of appropriate financial incentives will encourage them to do so. In this section we investigate the validity of the first presumption. One simple way to test whether superintendents have had any effect on our measures of school district performance is to assume that

$$
P_{i k}=\sum_{j=1}^{n} a_{j} d_{j}+\sum_{k=1}^{m} b_{k} I_{h t-1}+c_{i t}
$$

where $P_{a}$ is an estimated performance measure (either test score or tax rate) for school district $i$ in year $t, d_{j}$ is a dichotomous variable equal to one if the particular school district is district $j$ and zero otherwise, $n$ is the number of school districts in the sample (approxinnately 700), $I_{t-1}$ is a dichotomous variable equal to one if superintendent $k$ worked in school district $i$ in year $t-1$ and zero otherwise, and $m$ is the number of superintendents in the sample (approximately 1,000 ).

Equation (6) is a simple analysis of variance model in which a school district's estimated performance measure in a year is specified to depend only on the district and the particular superintendent employed in the district in the previous year. 14 If superintendents per se matter, at least some of the $b_{k}$ should prove to be nonzero.

Conceptually simple though it is, however, equation (6) entails estimating a model with approximately 1,700 coefficients, no simple computational task. Fortunately, first-differencing yields

$$
\begin{aligned}
P_{i t}-P_{i t-1}= & \sum_{k=1}^{m} b_{k}\left(I_{k t-1}-I_{k t-2}\right) \\
& +\left(\epsilon_{i t}-\epsilon_{i t}-1\right) .
\end{aligned}
$$

That is, the change in a performance

\footnotetext{
11 The one-year lag is assumed in the case of the rax rate measure because the tax rate in yeir $t$ is deterinined by the school board and superintendent in yeas 1 - 1. Although test scores in year $t$ conceivably could depend on the superintendents' actions in year $t$, a year lag seems reasonable in this case as well. Longer panels of data than we hase would permit experimentation with a variety of lag lengths.
}

index in a school district between year $t$ and year $t-1$ will be a function of the change in all of the superintendent variables. If the same superintendent was in the school district in years $t-1$ and $t-2$, the changes in all these superintendent variables will equal zero. If a change in the superintendent occurred, one variable will equal one and one variable will equal minus one for the district.

The majority of superintendents in our sample stayed in the same school district throughout the sample period; for these people, $I_{t-1}-I_{t-2}$ alwayn equaled zero, and thus their "variables" dropped out of the model. In practice, using performance data for $l=79-80,80-81$, and $81-82$ and superintendent data for $t-1=78-79$, $79-80$, and $80-81$ left us with roughly 1,000 "change observations" and 125 coefficients to estimate in equation (7). ${ }^{15} \mathrm{~A}$ simple $\mathbf{F}$ test of the hypothesis that each coefficient of the vector of $b_{k}$ coefficients equals zero is then a test of whether superintendents per se influence the school district performance measures.

Both the tax rate and sixth grade math test performance measures were used in the estimation, and in neither case could we reject the null hypothesis that each $b_{k}$ was equal to zero. That is, we found no evidence that knowledge of who the school superintendent was in one year can help in predicting a school district's tax rate performance measure or its sixth grade math test score performance measure in the following year. Thus, superintendents do not appear to have influenced our measures of school district performance.

Of course, a more complete analysis would experiment with at variety of differ. ent lags in equation (6) using larger

15 Our sample spans the 1978-79 to $1932-83$ academic years. We hase only threc years' performance data to use bere berause (1) the 1078-79 measures caunot be used, since we do not know who the superintendent was in 1977-78, and (2) we never compuled the 1982-83 muasures, since, in the absence of 1983-84 data on superintendents" salaries and job locations, they were not used in the analyses in prestious sections. 
sample sizes (more years' data). ${ }^{16}$ In addition, the weakness of our educational performance measures should be reemphasized. Data limitations have restricted us throughout our analysis to focusing on the lower tail of the achievement distribution in mathematics for one elementary grade level. More complete measures would focus attention on the upper tail, on other subjects, on achievement measures for older students (such as test scores, drop. out rates, high school graduation rates, and college attendance rates), and on variables that are less easily measured (such as the success with which students are taught to think critically or instilled with a sense of sociai responsibility). Clearly, the measure we use as an index of educational performance is measured with considerable error. It is therefore quite possible that we understate both superintendents' effects on educational performance and the effect of educational performance on superintendents' salary changes and mobility.

\section{Concluding Remarks}

Are school superintendents rewarded for their school districts' good performance by larger salary increases or greater opportunities for mobility to higherpaying positions? Although the evidence we have presented is somewhat ambiguous, our tentative answer is yes. The better a school district's tax rate performance measure, other things equal, the more likely that its superintendent will move to a higher-paying job the following year; and among "movers," the better the district's tax rate performance measure, the higher the new salary is likely to be. Also, the better the district's sixth grade mathematics test performance in the previous year, the larger are the salary increases for "stayers." Contrary to our expectations, however, this educational

\footnotetext{
14 For example. we found similar resulis (no apparent effect of school superinuendents on sclionl district performance) when we assumed that perfor. mance in periugl o was a function of the superinten. dent in period $1-2$.
}

performance index is negatively associated with salary increases for movers-a finding that gives us some pause as we draw conclusions.

Another important question is whether the rewards superintendents apparently receive for good performance by their districts (on the two measures we use) are great enough to induce them to work harder to improve that performance. Our study does not directly address that ques. tion, but judging by the quite modest effects we have found, as well as by the responses to the questionnaire item on the criteria school boards use in their evaluation of superintendents, we would be surprised if the answer were yes.

For example, the estimated cosfficients in Table 6 suggest that a superintendent who remained in the same district while his district's math test performance index held steady at one standard deviation above the mean performance index (which is zero) would receive an annual salary increase only 0.3 percentage points higher than that awarded a superintendent who remained in a district with only average performance on the same measure. ${ }^{17}$ If the two districts maintained these levels of performance over a ten-year period, the saiaries of the superintendents would diverge by only slightly more than 3 percentage points. Similarly, among superintendents who moved to another position, those whose districts' tax rate performance index was one standard deviation above the mean tax rate performance (which again is zero) would receive a salary increase upon moving only 1.7 percentage points higher than the salary increase given a "mean performing mover." 18 In neither case does the incentive seem strong enough to elicit much extra effort from a superintendent to improve his school district's performance.

\footnotetext{
${ }^{17}$ This increase is computed as the stayer coeflicient for the lagged math performance variable (.007) multiplied by the standard detiation of the math performance variable (.46).

is This increase is computed as the implied mover coefficien for the lagged tax rate perforinance variable $(.075)$ multiplied by the standard devintion of the tax rate perfornaluce variable $(.23)$.
} 
On the other hand, the coefficients in Table 5 do suggest that a district's tax rate performance substantially influences its superintendent's prospecis for mobility. Specifically, the probability of moving to a better-paying superintendency in New York State relative to the probability of remaining in the same district was $\mathbf{4 0}$ percent higher-and the probability of moving to a new superintendency paying less or no more than the original position relative to the probatility of remaining in the same district was 37 percent lowerfor a superintendent whose district's tax rate performance was one standard deviation above the mean than for a superintendent whose district's performance was only at the mean.9 ${ }^{19}$ Given the small number of superintendents who moved to new superintendencies in New York State, however, the ratios of these probabilities on average are so small-.098 (46/1207) and .016 (19/1207), respectively - that is seems unlikely that these mobility effects are large enough to provide appropriate incentives for superintendents to improve their districts' tax rate performance.

Our finding that the identity of a district's superintendent had no apparent connection with the values of our two performance measures for that district is open to several interpretations. First, it may be that the incentive iffects we have estimated are too weak to induce superintendents to try 10 influence these performance measures. Second, it is possible that

19 These effects are cakculated as exp((1.466)(.29)) tninus one and $\exp ((-2,006)(28)$ minus one. respectively. school superintendents actually have little control over their districts' tax rates or educational performance. Contradicting this interpretation, however, is that portion of the effective schools literature (see footnote 1 , above) that emphasizes the important roles school administrators play. Third, as noted above, the shortness of the time covered by the available data and errors in the measurement of our educational performance indexes may have resulted in our underestimating both superintendents' effects on school district performance and the effects of school district performance on superintendents' salary changes and mobility.

Identifying the correct explanation for the apparent irrelevance of superintendents' identity to the two measures of school performance we use will require additional research, some suggestions for which we have briefly discussed in this paper. Which (if any) of the interpretations mentioned above proves to be correct will surely be of interest to anyone who regards high educational performance and effective fiscal management as desirable goals for school districts. Clearly, it is too soon to state any firm policy recommendation. We are inclined, however, to take the results of both our econometric research and our survey findings at face value (that is, to accept, for the time being, the first interpretation) and to suggest to local school boards that they give consideration to building more incentives into school superintendents' compensation arrangements to encourage actions to influence educational quality and fiscal management.

\section{REFERENCES}

American Acsociation of School Adminiotrators

1979- Who' Who in Educational Administrution. Arling-

80 ton, Va.

Clinmberlain, $\mathbf{G}$.

1981 "On the Use of Panel Data." In J. Heckman and $B$. Singer, eds., The Anabssis of Longitudi. nal Labor Martat Data. New York: Academic Press.
Ehrenberg, Ronald G., Richard P. Chaykowoki, and Rindy A. Ehreaberg

1986 "Merit Pay for School Superintendents?" Cambridge, Mass.: National Bureau of Economic Research Working Paper No. 1954.

Goldatein, Gerald, and Ronald Ehrenberg

1976 "Executive Compensation in Municipalities." Southern Economic Journal, Vol. 43, No. 3, pp. 937-47. 


\section{Grilichen, Zvi}

1977 "Estimating the Returns to Schooling: Some Econometric Problems." Econometrica, Vol. 45, No. 1, pp. 1-22.

Haveaun, Jerry

1978 "Specification Tests in Econometrics." Econometrica, Vol. 46, No. 6, pp. 125-71.

Heckmun, James

1981 "Heterogeneity and State Dependence." In S. Rosen, ed., Studies in Labor Markets. Chicago: University of Chicago Press,

1979 "Sample Bias as a Specification Error." Econometrica, Vol, 47, No. 1, pp. 153-62.

Maddalh, G. 8.

1983 Limited-Dependent and Qualitative Variables in Econometrics. Cambridge, England: Cambridge Universily Press.

1977 Econometrits. New York: McGraw-Hill.
March, James C., and James C. March

1977 "Almost Random Careers: The Wisconsin School Superintendency, 1940-72." Administralize Science Qutatterly, Vol. 22, No. 9, Pp. 377-409.

Mundlak, Yalr

1978 "On the Pooling of Time-Series and CrossSection Data." Econometrica, Vol. 46, No. J, pp. 69-85.

National Cosmmisalon on Excellence in Education

1983 A Nation at Rist: The Imperative for Educational Reform. Washington, D.C.

Schmittlejn, David, and Donald Morrison

1981 "On Individual Level Inference in Job Duration Research: A Reexamination of the Wisconsin School Superintendents Study," Administrative Stience Quarterly, Vol. 26, No. 1. pp. 84-89. 